\title{
Genetic predictors of thyroid cancer outcome
}

\author{
Catarina Tavares ${ }^{1,2,3,{ }^{*}}$, Miguel Melo ${ }^{1,2,4,5,{ }^{*}}$, José Manuel Cameselle-Teijeiro ${ }^{6}$, \\ Paula Soares ${ }^{1,2,3,7}$ and Manuel Sobrinho-Simões ${ }^{1,2,3,7,8}$
}

${ }^{1}$ Instituto de Investigacão e Inovacão em Saúde, Universidade do Porto, 4200-135 Porto, Portugal, ${ }^{2}$ Cancer Biology, Institute of Molecular Pathology and Immunology of the University of Porto (IPATIMUP), Rua Dr Roberto Frias, s/n, 4200-465 Porto, Portugal, ${ }^{3}$ Medical Faculty, University of Porto, Al. Prof. Hernâni Monteiro, P-4200 Porto, Portugal, ${ }^{4}$ Endocrinology, Diabetes and Metabolism Department, Centro Hospitalar e Universitário de Coimbra, Praceta Mota Pinto, 3000-075 Coimbra, Portugal, ${ }^{5}$ Medical Faculty, University of Coimbra, Azinhaga de Santa Comba, 3000-548 Coimbra, Portugal, ${ }^{6}$ Department of Pathology, Medical Faculty, Servicio Gallego de Salud-SERGAS, Clinical University Hospital, University of Santiago de Compostela, 15705 Santiago de Compostela, Spain, ${ }^{7}$ Department of Pathology and Oncology, Medical Faculty of Porto University, Porto, Portugal and ${ }^{8}$ Department of Pathology, Hospital de S. João, Al. Prof. Hernâni Monteiro, P-4200 Porto, Portugal

*(C Tavares and M Melo contributed equally to this work)

Correspondence should be addressed to M Sobrinho-Simões Email ssimoes@ipatimup.pt

\begin{abstract}
Genetic predictors of outcome are reviewed in the context of a disease - cancer - that can be (too) simplistically described as a 'successful, invasive clone of our own tissues'. Context has many faces that determine a thyroid cancer patient's outcome beyond the influence of genetic markers. There is also plenty of evidence on the prognostic meaning of the interplay between genetics and context/microenvironment factors (encapsulation, degree of invasion, staging, etc.). This review addresses only genetic alterations detected by molecular methods in surgically resected specimens, thus ruling out immunohistochemistry and (F)ISH, despite their crucial relevance as topographically oriented methods. For the sake of the discussion, well-differentiated carcinomas were divided into two main morphologic types: papillary carcinoma (classic and most variants) displaying BRAFV600E mutations and RET/papillary thyroid carcinoma rearrangements and the group of follicular patterned carcinomas that encompasses follicular carcinoma and the encapsulated form of follicular variant of papillary carcinoma, displaying RAS mutations and PAX8/PPAR $\gamma$ rearrangement. TERT promoter mutations have been recently described (and associated with distant metastases and reduced survival) in papillary and follicular carcinomas, as well as in poorly differentiated and undifferentiated carcinoma. TP53 mutations, previously thought to be restricted to less differentiated carcinomas, were also detected in papillary and follicular carcinoma and found to carry a guarded prognosis. Besides their putative importance for targeted therapies, the prognostic meaning of such mutations is discussed per se and in the setting of concurrent BRAF mutation.
\end{abstract}

\section{Invited Author's profile}

M Sobrinho-Simões, MD, PhD is Professor and Director of the Department of Pathology and Oncology of Porto Medical Faculty, Chief of Service of Pathology at S. João Hospital and Director of the Institute of Molecular Pathology and Immunology of the University of Porto (PATIMUP), which he co-launched in 1989. His main interests are oncobiology and thyroid cancer in the frame of translational research. He has been particularly involved in the integration of ultrastructural, immunocytochemical and molecular data in pathology and oncology of endocrine organs. His research group has published seminal papers on GRIM-19 and Hürthle cell tumours, BRAF mutations in PTC and TERT promoter mutations in thyroid cancer.

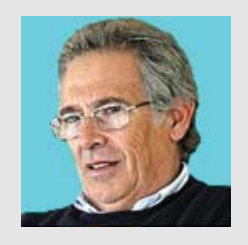

(C) 2016 European Society of Endocrinology Printed in Great Britain
Published by Bioscientifica Ltd. 


\section{Introduction}

Assuming that cancer can be defined, in an oversimplified way, as a 'highly regulated, successful invasive clone of our own tissues' or, in a less simplified but still too simplistic way, as a 'highly regulated, successful, invasive clone of our own tissues, involving a multistep accumulation of mutations in genes regulating major signalling pathways that are frequently heterogeneous genetically, epigenetically and phenotypically, as well as the cross talk of such mutations with cellular and extracellular alterations at the surrounding tissues', it does not make sense to discuss genetic predictors of thyroid cancer (or any other cancer type) outside host and surgical pathology context.

The aforementioned context has many faces that determine patients' outcomes beyond the influence of genetic markers. This applies to the age and/or gender of the patients, and the site, size and macroscopic characteristics of the cancer - namely, its pushing or infiltrative borders. The degree of invasiveness, both locally and at a distance, is measured by the TNM staging, which is the most powerful predictor of outcome of almost all cancer patients. The histological characteristics of the cancer are also a major factor of prognosis: morphological subtype, degree of differentiation, extension of necrosis, mitotic index and signs of invasion (parenchymatous, lymphovascular and to adjacent organs). The histological context can be, and frequently is, enriched by immunohistochemical data that allow to evaluate more precisely cell proliferation, overexpression (or misplacement) of oncogene products and underexpression (or, again, misplacement) of tumour-suppressor gene products and the number and the type of cells involved in the immunomodulation of cancer development.

The sort of molecular approach that immunohistochemistry provides is also achieved, and frequently reinforced, by in situ demonstration of gene rearrangement and gene amplification (FISH is frequently the best method to detect such genetic alterations). Both immunohistochemistry and in situ methods provide, furthermore, topographic information that complements the molecular data and are often crucial for understanding carcinogenesis. This has been demonstrated, for instance, by Eloy et al. (1) who showed that the interaction between transforming growth factor beta/Smad pathway activation and BRAF mutation plays different roles in circumscribed and infiltrative papillary thyroid carcinoma (PTC); in the latter, the interaction is associated with epithelialto-mesenchymal transition and local invasion, as well as to nodal metastization of infiltrative PTCs (1).
Thyroid carcinomas are classified according to the cell type they derive from, their degree of differentiation and their cytoarchitecture. Follicular cell-derived tumours comprise well-differentiated thyroid carcinoma (WDTC), poorly differentiated thyroid carcinoma (PDTC) and undifferentiated thyroid carcinoma (UTC). The welldifferentiated group encompasses, according to cytoarchitecture and nuclear features of the neoplastic cells, follicular thyroid carcinoma (FTC) and PTC, with the latter having two main variants: classic PTC (CPTC) and follicular variant PTC (FVPTC). The minority of carcinomas that derive from parafollicular $\mathrm{C}$ cells are named medullary thyroid carcinoma (2).

In this review, we will just focus on genetic alterations detected by molecular methods in surgically resected specimens, thus skipping their usefulness in cytopathology. To keep the paper within an adequate size, we will only address the importance of the genetic predictors of outcome of patients with follicular cellderived carcinomas displaying good or moderate differentiation, thus avoiding medullary carcinoma and UTC. PDTC will be discussed together with the respective better differentiated counterparts PTC and its variants, namely, FVPTC and FTC.

\section{Clinico-pathological factors vs genetic predictors of outcome}

In a recent article on the usefulness of molecular biomarkers in thyroid cancer, we concluded that, for the moment, clinical and histopathological prognostic factors remain much more important than genetic factors for diagnostic and prognostic purposes (3). This conclusion is, however, challenged almost every day by the publication of new molecular data in the different types of thyroid cancer. The most important of such publications was the 'Integrated genomic characterization of papillary thyroid carcinoma' that provided a detailed description of the genomic landscape of 496 cases of PTC under the auspices of The Cancer Genome Atlas (TCGA) Research Network Initiative (4).

Besides a huge amount of genetic and epigenetic information that will take time to fully understand, it is interesting to realize that the aforementioned study (4) confirmed the existence of two main genetic types of differentiated thyroid carcinoma (DTC) that correspond to CPTC (and some variants of PTC such as the tall cell and Warthin-like variant) and to the group of follicular 
patterned carcinomas that encompass FVPTC, as our group and others have suggested years ago $(5,6,7)$. The absence of solid prospective studies on thyroid cancer and the close relationship between clinical, pathological, immunohistochemical and genetic factors turn very difficult to discuss out of the global context the prognostic role played by the latter (8).

Of the numerous genetic alterations detected in WDTC and PDTC, we included in the present review those that are more prevalent and/or seem to play a more important prognostic role. It is the case of BRAF, RAS, TERT promoter and TP53 mutations and of RET/PTC and PAX8/PPAR $\gamma$ rearrangements.

\section{RET/PTC and PAX8/PPAR $\gamma$ rearrangements}

RET/PTC rearrangements are quite frequent in PTC, whereas PAX8/PPAR $\gamma$ rearrangement is often detected in follicular patterned lesions (FVPTC and FTC) $(3,5,6$, $7,9)$; the overall evidence indicates that tumours with either of these rearrangements rarely evolve to less differentiated forms (i.e. their prevalence is very low in PDTC and UTC). RET/PTC is a chimeric gene generated by the fusion of the RET tyrosine kinase (TK) domain with the $5^{\prime}$ terminal region of genes that are constitutively expressed in thyroid follicular cells (10) allowing dimerization of the RET TK domain and its constitutive activation. The most frequent forms of this oncogene in PTC are RET/PTC1 and RET/PTC3, both arising from chromosome 10 inversions (11). RET/PTC1 rearrangement appears to be associated with small, classic type PTC displaying low proliferation and occurring in young patients $(12,13,14,15)$. At variance with this, RET/PTC3 rearrangement is prevalent in the solid variant of PTC that is frequent in children and was often found in PTCs occurring in the setting of the Chernobyl accident (16), being more prone to a more aggressive behaviour (13, 14, 15, 17). Despite being associated with signs of clinical aggressiveness (namely nodal and lung metastases), cases of solid variant of PTC arising in young patients, with or without RET/PTC3 rearrangement, respond well to radioactive iodine (RAI) treatment and are not significantly associated with a worse survival of the patients.

Taking the data on record in the literature as well as our own experience into account, it may be concluded that the prognostic value of RET/PTC rearrangement in thyroid cancer has not been fully clarified yet.

$P A X 8 / P P A R \gamma$ rearrangement has been associated with some adverse prognostic features (e.g. multifocality and vascular invasion) in some series, but the gathered evidence is not strong enough to identify this rearrangement as a genetic predictor of outcome in thyroid cancer $(9,18)$. Furthermore, $P A X 8 / P P A R \gamma$ rearrangements have been also detected in $14 \%$ of the cases of follicular thyroid adenoma (FTA) (19).

\section{RAS mutations and prognosis}

RAS are small GTPase-proteins that act as a molecular switch propagating signals from TK and non-TK receptors and activating the MAPK and other signalling pathways. RAS mutations are more prevalent and seem to be more relevant as a prognostic indicator in follicular patterned lesions (FVPTC, FTC and, namely, PDTC) than in cPTC (18). All of the three RAS genes ( $\mathrm{H}, \mathrm{K}$ and N-RAS) were shown to be mutated in both benign and malignant thyroid tumours but the frequency of the mutations is higher in FTC (36\%), PDTC (55\%) and UTC (52\%) and more frequently affects the N-RAS gene (20).

RAS mutations are less prevalent in benign and malignant Hürthle cell tumours (5 and 11\% respectively) than in their non-Hürthle cell counterparts and less prevalent in PTC $(10 \%)$ than in FTC $(25-30 \%)(7,20)$. Within PTC, RAS mutations are rare in its classic form, whereas in FVPTC, its prevalence falls within the range of other follicular patterned tumours ( 25\%) (6).

The controversy on the prognostic value of RAS mutations in thyroid cancer results partially, at least, from the fact that RAS mutations are present along all of the whole spectrum of thyroid lesions, from FTA to the deadly UTC. Garcia Rostan et al. (21) have shown that patients with RAS mutated carcinomas, namely PDTC, harbour distant metastases more frequently and have higher mortality, being RAS mutations an independent predictor of poor survival (21). Other studies disclosed a similar association between (N) RAS mutation and distant metastases and/or lower survival in FTC $(22,23)$.

The assumption that RAS mutations can predispose to differentiation loss in thyroid cancer derives from their presence in DTC with areas of dedifferentiation and from their greater prevalence in PDTC and UTC than in DTC (24).

It has been difficult to demonstrate the prognostic value of RAS mutations due to the relatively small size of the majority of the series (in particular concerning FTC, PDTC and UTC that are less frequent than PTC) and the too short follow-up in most situations. Large, multicentric studies will be necessary to establish definitely the prognostic value of RAS mutations. 


\section{BRAF and NIS expression}

BRAF gene encodes a serine/threonine kinase that belongs to the RAS-RAF-MEK-ERK-MAP kinase pathway, whose biological role is to mediate cellular responses to growth factors. There are several BRAF mutations, the BRAFT1796A (in exon 15) is largely the more prevalent, leading to a substitution of a valine by a glutamic acid at position 600. Such a mutation causes increased BRAF kinase activity and the subsequent phosphorylation of MEK1/2 and ERK1/2, turning the activation of the MAP kinase pathway independent from upstream factors activation (25).

BRAFV600E mutation is the most prevalent point mutation in PTC, being present in 36-83\% of cases. It rarely co-exists with other prevalent genetic events such as RET/PTC rearrangement or RAS mutation (18). BRAFV600E mutation exhibits a strong genotype-phenotype association; it is (almost) exclusively detected in PTC exhibiting a papillary or mixed follicular/papillary growth pattern, regardless of being a cPTC or any of the PTC variants (other than the encapsulated FVPTC) (5).

Besides the frequent BRAFV600E mutation, other alterations were detected in the BRAF gene in PTCs: the BRAFK601E mutation, which occurs mainly in FVPTC ( $<10 \%$ of the cases) (5), and the in-frame deletion VK600-1E that has been detected in rare cases of solid variant of PTC. BRAF rearrangements, namely the AKAP9BRAF fusion, were also described as rare events preferentially found in radiation-induced PTC (18). At present, there is not enough evidence to evaluate the putative prognostic role of the aforementioned rare BRAF alterations.

Although functional studies, using thyroid-targeted BRAFV600E transgenic mice (26) and BRAFV600E transfected thyroid cell lines (27), indicate that BRAF mutations lead to a more 'aggressive type' of PTC, several other studies, addressing the correlation between BRAFV600E and the clinical features of PTC, provided discrepant results (see below).

Some studies reported significant associations between BRAF mutation and poor prognostic indicators like older age $(28,29)$, male gender $(30,31)$, extrathyroid extension $(28,32)$, regional metastases $(29,32)$, distant metastases (33), higher tumour staging (28, 32, 33), tumour size $(31,34,35)$ and tumour recurrence $(32,36)$. Other studies have not observed the aforementioned associations (37, 38, 39). Furthermore, Elisei et al. (40) have demonstrated that the search for BRAFV600E mutation may prove useful to modulate the treatment among low-risk PTC patients, those who require less or more aggressive treatment. Recently, a multicenter retrospective study showed that BRAFV600E was significantly associated with increased cancer-related mortality among patients with PTC, but the association was not independent of several clinico-pathological features of aggressiveness (41).

We observed that BRAFV600E PTCs tended to occur in older patients and did not exhibit a significant association with signs of clinico-pathological aggressiveness - namely larger size, extrathyroidal extension, vascular invasion and lymph node metastases $(5,8)$ - or poor circumscription (8). This does not mean, however, that BRAF mutation cannot contribute for progression of PTC toward less differentiated carcinomas in the appropriate context, because our group and others $(28,33,42)$ detected BRAFV600E mutation in $10-35 \%$ of UTC.

Despite the BRAF mutation controversial association with guarded prognostic features, its association with a decrease in expression of several 'thyroid specific genes' or 'iodine handling genes' $(36,43,44)$ is widely acknowledged. The association of BRAF mutation with the loss of RAI avidity in recurrent PTC has been confirmed in vitro and in vivo $(36,45)$. It was recently shown that MEK inhibition may restore RAI incorporation, turning BRAF and/or MEK inhibitors into promising targets to treat RAIrefractory thyroid cancers $(45,46)$.

\section{TERT promoter mutations}

About two-thirds of thyroid carcinomas display telomerase activation that is more frequent in UTC than in DTC (42). Capezzone et al. (47) observed telomerase activity in most sporadic and familial malignant thyroid tumours, as well as in some adenomas. Recently, mutations in the promoter region of the telomerase (TERT) gene were reported in follicular cell-derived thyroid carcinomas (FCDTC) $(48,49,50)$. These mutations occur in two hotspot positions, located at -124 and -146 bp upstream from the ATG start site $(-124 \mathrm{G}>\mathrm{A}$ and $-146 \mathrm{G}>\mathrm{A}, \mathrm{C}>\mathrm{T}$ on opposite strand) and confer enhanced TERT promoter activity, putatively by generating a consensus-binding site (GGAA) for ETS transcription factors within the TERT promoter region (51).

In a large series of 469 carcinomas, we found TERT promoter mutations in $7.5 \%$ of PTC, $17.1 \%$ of FTC, $29.0 \%$ of PDTC and $33.0 \%$ of UTC (52). This stepwise increase in the frequency of TERT promoter mutations from well to poorly differentiated and undifferentiated carcinomas was also reported in other studies $(49,50)$. No TERT promoter mutations were found in normal tissues, benign lesions or 
medullary thyroid carcinomas. Like RAS mutations, the frequency of TERT promoter mutations seems to be lower in tumours with oncocytic features than in their nononcocytic counterparts; these observations reinforce the assumption that oncocytic tumours have a different set of molecular alterations and probably also alternative mechanisms for cell survival $(53,54,55)$. The majority (about $80 \%$ ) of mutated cases present the $-124 \mathrm{G}>\mathrm{A}$ mutation. In PTC, TERT promoter mutations were significantly more frequent in $B R A F$ mutated tumours $(50,52)$. TERT promoter mutations were associated with increased mRNA expression, and this increase was more pronounced in tumours harbouring both BRAF and TERT promoter mutations (48).

Several studies analysed the relationship between TERT promoter mutations and clinico-pathological features $(49,50,52,56,57)$, and four studies also analysed the implications of the presence of these mutations on patients' clinical outcomes $(52,56,58,59)$. TERT promoter mutations were associated with older age of the patients at diagnosis, larger tumour size, distant metastases and a higher stage in several studies $(50,52,57)$. The association with distant metastases seems to be particularly consistent and has been reported in most of the studies, strongly suggesting that there is a link between TERT promoter mutations and the metastatic potential of FCDTC. From the clinical standpoint, this association is extremely relevant because distant metastases are major determinants of prognosis, especially in older patients (60).

In our study (52), patients with DTC harbouring TERT promoter mutations were less prone to be disease free at the end of follow-up, and similar results were found in three other studies $(56,58,59)$. Our study also showed that patients with TERT-mutated tumours were submitted to more treatments with radioiodine with higher cumulative doses, as well as to other treatment modalities like surgery for recurrent disease, external beam irradiation or treatment with TK inhibitors (52). Furthermore, patients with tumours harbouring TERT promoter mutations had increased disease-specific mortality, and this finding was independent of age and gender (52).

As previously mentioned, TERT-mutated PTC harbours more frequently BRAF mutations than TERTwt tumours. Horn et al. (51) advanced that the mutation creates newly consensus binding sites for TCF subfamily transcription factors (Elk1 and Elk4) that can be activated by BRAF. Our results in TERT mRNA expression corroborated this assumption, showing an increased TERT expression in tumours harbouring BRAF and TERT mutation (48). Because BRAF has also been associated with worse prognosis in some studies, several authors hypothesized that both mutations could cooperate toward a worse prognosis $(50,61)$. One still ignores the mechanism behind the putative cooperation between BRAF and TERT promoter mutation. It is nevertheless tempting to speculate, considering the pro-senescent effect of BRAF mutation alone (62), that TERT promoter mutations may contribute to abrogate such effect through their, role leading to evasion from senescence $(63,64,65)$. Taking into account that the prognostic value of BRAF is currently under debate and that TERT promoter mutations were independently associated with aggressive clinicopathological features and worse outcome in all of the large series published to date (66), we think that, at present, the most important question is to clarify, whether or not, after controlling the clinical importance of TERT mutations, $B R A F$ goes on adding a significant prognostic value (66). Multicentric studies with large series of patients will be necessary to clarify if the 'addition' of BRAF mutational status to a TERT-mutated tumour has indeed value for prognostic stratification (66).

\section{TP53 mutations}

Most TP53 mutations lead to the expression of a mutant protein or, less commonly, to its absence $(67,68)$. In thyroid carcinomas, TP53 mutations are not different from those of cancers at other sites and have been described in exons 5-9, with 273 being the codon most often altered $(42,67,69,70,71,72,73)$. No p53 expression or mutation has been found in normal thyroid or in benign lesions, including follicular adenoma, adenomatous goitre and chronic thyroiditis $(72,73,74,75,76)$. For years it was repeated that more than $98 \%$ of DTC (PTC and FTC) had a normal TP53 gene $(18,69,70,71,72,73,75$, $77)$, even when cases secondary to radiation exposure were included (78). This scenario may be changing due to the utilization of next-generation sequencing; using this methodology, Nikiforova et al. (79) reported the presence of TP53 mutations in 3.5\% of PTC (2/57) and in four of 36 FTC (11.1\%); the four FTC cases were oncocytic carcinomas and three were widely invasive (75). In the recent TCGA study (4), TP53 mutations were detected in $0.7 \%$ of PTC thus confirming their scarcity in PTC, but no clinicohistopathological data were provided on the mutated cases. The results of the study by Nikiforova et al. (75) study regarding the high clinical aggressiveness of TP53 mutated DTC fit with previously reported results. A small proportion of aggressive PTC are associated with TP53 mutations and/or p53 expression; the tall cell variant of 
PTC is associated with a significantly higher rate of p53 than common PTC (80). Positivity for p53 protein has been detected in rare aggressive thyroid tumours such as a mixed columnar and tall cell variant of PTC (81) and a squamous cell carcinoma associated with the tall cell variant of PTC (82). Positivity for p53 protein has also been reported in some aggressive cases of the cribriformmorular variant of PTC $(83,84)$. Immunohistochemical evaluation of the columnar cell variant of PTC showed a predominantly weak nuclear p53 staining in both indolent and aggressive tumours (81).

Loss of cellular polarity/cohesiveness, hobnail features and micropapillary structures, either alone or in combination, are independent predictive factors for lymph node metastasis both in common PTC and in papillary microcarcinoma $(82,83,84,85)$. All of these peculiar morphological features are characteristic of the so-called micropapillary/hobnail variant of PTC $(85,86,87,88,89)$, an aggressive type of PTC carrying poor outcome, which is consistently positive for p53 $(85,86,87,89)$ at the immunohistochemical level. Hobnail features were most commonly observed in association with PDTC and UTC (90). These features have also been associated with other histologic variants that are known to be more clinically aggressive, such as increased mitotic activity and/or necrosis and lymph node metastases at presentation. It has therefore been suggested that hobnail features may be a manifestation of 'higher-grade transformation' (90). The recent observation by our group (91) of two fatal cases of the micropapillary/hobnail variant of PTC positive for $\mathrm{p} 53$ by immunohistochemistry (Fig. 1) and TP53 mutated at the molecular level with progression to UTC supports the involvement of p53 in such transformation $(90,92)$. Inactivating TP53 mutations have been reported in about $26 \%$ of PDTC $(71,73,85)$ and in more than $60 \%$ of UTC $(42,69,70,71,73,85)$. The results of the studies based on the detection of nuclear accumulation of p53 protein $(73,74,75,76,86,87)$ fit with molecular studies. p53 expression is more obvious in areas showing active infiltrative growth and/or at the periphery in PDTC, and widespread positivity for p53 is characteristic of UTC. The analysis of TP53 mutations and/or p53 expression in PTC co-existing with UTC has shown that p53 expression/ mutation is limited to the undifferentiated components (70, 71, 86, 88). Moreover, re-expression of WT p53 in human UTC cell lines with a mutated p53 has been associated with re-expression of the paired box domain transcription factor Pax-8, thyroglobulin, thyroperoxidase and TSH receptor $(72,89)$. All of these findings strongly support that TP53 inactivation plays an important role in

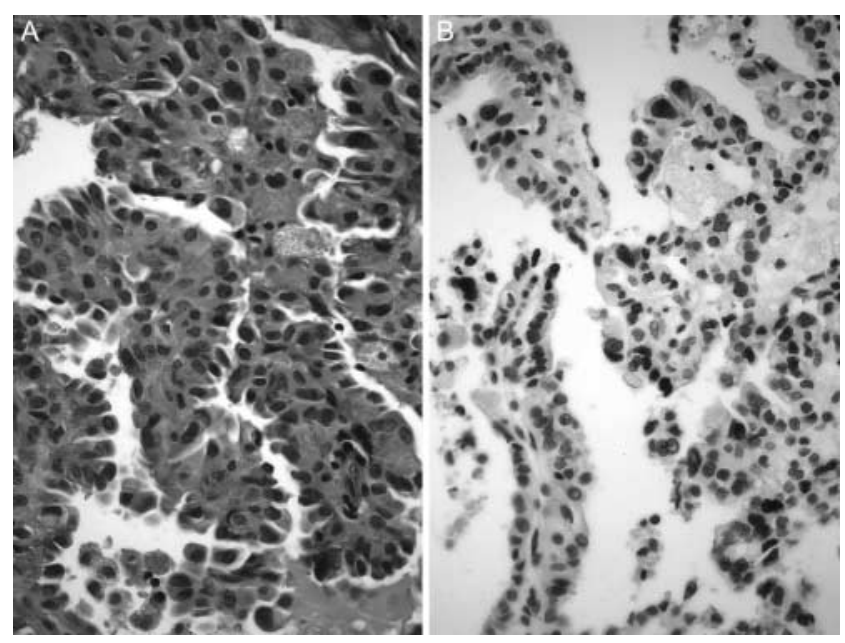

\section{Figure 1}

Micropapillary/hobnail variant of PTC. (A) The papillary structures are lined by cells with dense eosinophilic cytoplasm and the nuclei placed in the apex of the cytoplasm producing a surface bulge (hobnail appearance). There are also areas of cellular discohesiveness and micropapillary pattern $(\mathrm{H} \& \mathrm{E}, 400 \times)$. (B) The nuclei of the tumour cells show strong positivity for p53 (clone DO-7, Dako, Denmark, 400×).

the progression from differentiated to undifferentiated carcinoma, as a final event in the tumourigenic process, contributing to the highly aggressive phenotype of these tumours (90).

\section{miRNA and IncRNA in thyroid cancer outcome}

Of the numerous molecules and mechanisms described in recent years in the oncology field, miRNA and lncRNA arise as major players due to their action on the modulation of known cancer genes and/or their products (oncogenes, tumour suppressor genes and apoptotic proteins).

It has been hypothesized that some of the miRNA and/or lncRNA (or a set of) can help in the differential diagnosis of benign and malignant tumours, however scarce information is available regarding their putative role on prognosis. Nevertheless, some miRNA have been repeatedly found dysregulated in thyroid cancer, in particular in PTC (miR-146b, miR-181b, miR-187, miR221 and miR-222) and the same set of molecules has been associated with tumour aggressiveness in some studies (92). Unfortunately, the relevant set of miRNAs varies from one report to the other, turning difficult or even impossible to draw, at present, any meaningful conclusions. 
The same holds true concerning the available data on IncRNAs. The complexity of the available evidence is huge because these long (longer than $200 \mathrm{nt}$ ) RNAs can play a role at both the transcriptional and the post-transcriptional gene regulation level. IncRNAs NAMA, AK023948 and PTCSC3AA (PTC susceptibility candidate 3 ) are among the (yet) reduced number of IncRNAs that have been associated with PTC $(93,94)$. Until now it has not been possible to ascertain any role to lncRNA in the prognosis of thyroid cancer patients.

\section{Final remarks}

The importance of genetic markers for predicting thyroid cancer outcome is limited by the pre-eminence of clinical, histopathological, immunological and other contextdriven features. Despite this, there is enough evidence to claim that TERT promoter mutations and TP53 mutations are major molecular biomarkers of prognosis and to suggest that BRAF and RAS mutations may also play a prognostic role in some conditions. Besides prognosis, the aforementioned mutations and the respective molecular pathways, as well as other genetic and epigenetic alterations recently identified by the Cancer Genome Atlas (4), will probably serve as targets for the so-called personalized therapy.

\section{Declaration of interest}

The authors declare that there is no conflict of interest that could be perceived as prejudicing the impartiality of the review.

\section{Funding}

This study was supported by FCT, the Portuguese Foundation for Science and Technology through a PhD grant to $C$ Tavares. Further funding was obtained from the project 'Microenvironment, metabolism and cancer' that was partially supported by Programa Operacional Regional do Norte (ON.2 - O Novo Norte) under the Quadro de Referência Estratégico Nacional (QREN) and the Fundo Europeu de Desenvolvimento Regional (FEDER). IPATIMUP integrates the i3S Research Unit, which is partially supported by FCT. This study was funded by FEDER funds through the Operational Programme for Competitiveness Factors - COMPETE and National Funds through FCT, under the project PEst-C/SAU/LA0003/2013. The work of J M Cameselle-Teijeiro was supported by grant PI12/00749FEDER from Instituto de Salud Carlos III, Ministry of Economy and Competitiveness, Madrid, Spain.

\section{References}

1 Eloy C, Santos J, Cameselle-Teijeiro J, Soares P \& Sobrinho-Simoes M. TGF- $\beta$ /Smad pathway and BRAF mutation play different roles in circumscribed and infiltrative papillary thyroid carcinoma. Virchows Archiv 2012460 587-600. (doi:10.1007/s00428-012-1234-y)
2 Rosai JD, Frable WJ \& Tallini G. In Tumors of the Thyroid \& Parathyroid Glands. Chapter 9, pp 500-530. American Registry of Pathology: Washington DC, 2014.

3 Soares P, Celestino R, Melo M, Fonseca E \& Sobrinho-Simoes M. Prognostic biomarkers in thyroid cancer. Virchows Archiv 2014464 333-346. (doi:10.1007/s00428-013-1521-2)

4 Cancer Genome Atlas Research N. Integrated genomic characterization of papillary thyroid carcinoma. Cell 2014159 676-690. (doi:10.1016/ j.cell.2014.09.050)

5 Trovisco V, Soares P, Preto A, de Castro IV, Lima J, Castro P, Maximo V, Botelho T, Moreira S, Meireles AM et al. Type and prevalence of BRAF mutations are closely associated with papillary thyroid carcinoma histotype and patients' age but not with tumour aggressiveness. Virchows Archiv 2005446 589-595. (doi:10.1007/s00428-005-1236-0)

6 Castro P, Rebocho AP, Soares RJ, Magalhaes J, Roque L, Trovisco V, Vieira de Castro I, Cardoso-de-Oliveira M, Fonseca E, Soares P et al. PAX8-PPAR $\gamma$ rearrangement is frequently detected in the follicular variant of papillary thyroid carcinoma. Journal of Clinical Endocrinology and Metabolism 200691 213-220. (doi:10.1210/jc.2005-1336)

7 Nikiforov YE \& Nikiforova MN. Molecular genetics and diagnosis of thyroid cancer. Nature Reviews. Endocrinology 20117 569-580. (doi:10.1038/nrendo.2011.142)

8 Eloy C, Santos J, Soares P \& Sobrinho-Simoes M. The preeminence of growth pattern and invasiveness and the limited influence of BRAF and RAS mutations in the occurrence of papillary thyroid carcinoma lymph node metastases. Virchows Archiv 2011459 265-276. (doi:10.1007/ s00428-011-1133-7)

9 Armstrong MJ, Yang H, Yip L, Ohori NP, McCoy KL, Stang MT, Hodak SP, Nikiforova MN, Carty SE \& Nikiforov YE. PAX8/PPAR $\gamma$ rearrangement in thyroid nodules predicts follicular-pattern carcinomas, in particular the encapsulated follicular variant of papillary carcinoma. Thyroid 201424 1369-1374. (doi:10.1089/thy.2014.0067)

10 Fusco A, Grieco M, Santoro M, Berlingieri MT, Pilotti S, Pierotti MA, Della Porta G \& Vecchio G. A new oncogene in human thyroid papillary carcinomas and their lymph-nodal metastases. Nature 1987 328 170-172. (doi:10.1038/328170a0)

11 Romei C \& Elisei R. RET/PTC translocations and clinico-pathological features in human papillary thyroid carcinoma. Frontiers in Endocrinology 20123 54. (doi:10.3389/fendo.2012.00054)

12 Soares P, Fonseca E, Wynford-Thomas D \& Sobrinho-Simoes M. Sporadic ret-rearranged papillary carcinoma of the thyroid: a subset of slow growing, less aggressive thyroid neoplasms? Journal of Pathology 1998185 71-78. (doi:10.1002/(SICI)1096-9896(199805)185:1< 71::AID-PATH42>3.0.CO;2-S)

13 Thomas GABH, Cook HA, Williams ED, Nerovnya A, Cherstvoy ED, Tronko ND, Bogdanova TI, Chiappetta G, Viglietto G, Pentimalli F et al. High prevalence of RET/PTC rearrangements in Ukrainian and Belarussian post-chernobyl thyroid papillary carcinomas: a strong correlation between RET/PTC3 and the solid-follicular variant. Journal of Clinical Endocrinology and Metabolism 199984 4232-4238. (doi:10.1210/jcem.84.11.6129)

14 Nikiforov YE. RET/PTC rearrangement in thyroid tumors. Endocrine Pathology 200213 3-16. (doi:10.1385/EP:13:1:03)

15 Mochizuki KKT, Nakazawa T, Iwashina M, Kawasaki T, Nakamura N, Yamane T, Murata S, Ito K, Kameyama K, Kobayashi M et al. RET rearrangements and BRAF mutation in undifferentiated thyroid carcinomas having papillary carcinoma components. Histopathology 201057 444-450. (doi:10.1111/j.1365-2559.2010.03646.x)

16 Nikiforov YE, Rowland JM, Bove KE, Monforte-Munoz H \& Fagin JA. Distinct pattern of ret oncogene rearrangements in morphological variants of radiation-induced and sporadic thyroid papillary carcinomas in children. Cancer Research $1997 \mathbf{5 7}$ 1690-1694.

17 Sugg SL, Ezzat S, Zheng L, Freeman JL, Rosen IB \& Asa SL. Oncogene profile of papillary thyroid carcinoma. Surgery 1999125 46-52. (doi:10.1016/S0039-6060(99)70287-4) 
18 Sobrinho-Simoes M, Maximo V, Rocha AS, Trovisco V, Castro P, Preto A, Lima J \& Soares P. Intragenic mutations in thyroid cancer. Endocrinology and Metabolism Clinics of North America 200837 333-362, viii. (doi:10.1016/j.ecl.2008.02.004)

19 Marques AR, Espadinha C, Catarino AL, Moniz S, Pereira T, Sobrinho LG \& Leite V. Expression of PAX8-PPAR $\gamma 1$ rearrangements in both follicular thyroid carcinomas and adenomas. Journal of Clinical Endocrinology and Metabolism 200287 3947-3952. (doi:10.1210/jcem. 87.8.8756)

20 Howell GM, Hodak SP \& Yip L. RAS mutations in thyroid cancer. Oncologist 201318 926-932. (doi:10.1634/theoncologist.2013-0072)

21 Garcia-Rostan G, Zhao H, Camp RL, Pollan M, Herrero A, Pardo J, Wu R, Carcangiu ML, Costa J \& Tallini G. ras mutations are associated with aggressive tumor phenotypes and poor prognosis in thyroid cancer. Journal of Clinical Oncology 200321 3226-3235. (doi:10.1200/JCO.2003. 10.130)

22 Jang EK, Song DE, Sim SY, Kwon H, Choi YM, Jeon MJ, Han JM, Kim WG, Kim TY, Shong YK et al. NRAS codon 61 mutation is associated with distant metastasis in patients with follicular thyroid carcinoma. Thyroid 201424 1275-1281. (doi:10.1089/thy.2014.0053)

23 Fukahori M, Yoshida A, Hayashi H, Yoshihara M, Matsukuma S, Sakuma Y, Koizume S, Okamoto N, Kondo T, Masuda M et al. The associations between RAS mutations and clinical characteristics in follicular thyroid tumors: new insights from a single center and a large patient cohort. Thyroid 201222 683-689. (doi:10.1089/thy.2011.0261)

24 Zhu Z, Gandhi M, Nikiforova MN, Fischer AH \& Nikiforov YE. Molecular profile and clinical-pathologic features of the follicular variant of papillary thyroid carcinoma. An unusually high prevalence of ras mutations. American Journal of Clinical Pathology 2003120 71-77. (doi:10.1309/ND8D9LAJTRCTG6QD)

25 Davies H, Bignell GR, Cox C, Stephens P, Edkins S, Clegg S, Teague J, Woffendin $\mathrm{H}$, Garnett MJ, Bottomley W et al. Mutations of the BRAF gene in human cancer. Nature 2002417 949-954. (doi:10.1038/ nature00766)

26 Knauf JA, Ma X, Smith EP, Zhang L, Mitsutake N, Liao XH, Refetoff S, Nikiforov YE \& Fagin JA. Targeted expression of BRAFV600E in thyroid cells of transgenic mice results in papillary thyroid cancers that undergo dedifferentiation. Cancer Research 200565 4238-4245. (doi:10.1158/0008-5472.CAN-05-0047)

27 Melillo RM, Castellone MD, Guarino V, De Falco V, Cirafici AM, Salvatore G, Caiazzo F, Basolo F, Giannini R, Kruhoffer M et al. The RET/PTC-RAS-BRAF linear signaling cascade mediates the motile and mitogenic phenotype of thyroid cancer cells. Journal of Clinical Investigation 2005115 1068-1081. (doi:10.1172/JCI200522758)

28 Nikiforova MN, Kimura ET, Gandhi M, Biddinger PW, Knauf JA, Basolo F, Zhu Z, Giannini R, Salvatore G, Fusco A et al. BRAF mutations in thyroid tumors are restricted to papillary carcinomas and anaplastic or poorly differentiated carcinomas arising from papillary carcinomas. Journal of Clinical Endocrinology and Metabolism 200388 5399-5404. (doi:10.1210/jc.2003-030838)

29 Kebebew E, Weng J, Bauer J, Ranvier G, Clark OH, Duh QY, Shibru D, Bastian B \& Griffin A. The prevalence and prognostic value of BRAF mutation in thyroid cancer. Annals of Surgery 2007246 466-470 (discussion 470-471). (doi:10.1097/SLA.0b013e318148563d)

$30 \mathrm{Xu}$ X, Quiros RM, Gattuso P, Ain KB \& Prinz RA. High prevalence of BRAF gene mutation in papillary thyroid carcinomas and thyroid tumor cell lines. Cancer Research 200363 4561-4567. (doi:10.1111/j. 1365-2265.2006.02605.x)

31 Kim TY, Kim WB, Rhee YS, Song JY, Kim JM, Gong G, Lee S, Kim SY, Kim SC, Hong SJ et al. The BRAF mutation is useful for prediction of clinical recurrence in low-risk patients with conventional papillary thyroid carcinoma. Clinical Endocrinology 200665 364-368. (doi:10.1111/j.1365-2265.2006.02605.x)

32 Xing M. BRAF mutation in thyroid cancer. Endocrine-Related Cancer 200512 245-262. (doi:10.1677/erc.1.0978)
33 Namba H, Nakashima M, Hayashi T, Hayashida N, Maeda S, Rogounovitch TI, Ohtsuru A, Saenko VA, Kanematsu T \& Yamashita S. Clinical implication of hot spot BRAF mutation, V599E, in papillary thyroid cancers. Journal of Clinical Endocrinology and Metabolism 200388 4393-4397. (doi:10.1210/jc.2003-030305)

34 Oler G \& Cerutti JM. High prevalence of BRAF mutation in a Brazilian cohort of patients with sporadic papillary thyroid carcinomas: correlation with more aggressive phenotype and decreased expression of iodide-metabolizing genes. Cancer 2009115 972-980. (doi:10.1002/ cncr.24118)

35 Elisei R, Ugolini C, Viola D, Lupi C, Biagini A, Giannini R, Romei C, Miccoli P, Pinchera A \& Basolo F. BRAF(V600E) mutation and outcome of patients with papillary thyroid carcinoma: a 15-year median followup study. Journal of Clinical Endocrinology and Metabolism 200893 3943-3949. (doi:10.1210/jc.2008-0607)

36 Riesco-Eizaguirre G, Gutierrez-Martinez P, Garcia-Cabezas MA, Nistal M \& Santisteban P. The oncogene BRAF V600E is associated with a high risk of recurrence and less differentiated papillary thyroid carcinoma due to the impairment of $\mathrm{Na}+/ \mathrm{I}-$ targeting to the membrane. Endocrine-Related Cancer 200613 257-269. (doi:10.1677/erc.1.01119)

37 Fugazzola L, Puxeddu E, Avenia N, Romei C, Cirello V, Cavaliere A, Faviana P, Mannavola D, Moretti S, Rossi S et al. Correlation between B-RAFV600E mutation and clinico-pathologic parameters in papillary thyroid carcinoma: data from a multicentric Italian study and review of the literature. Endocrine-Related Cancer 200613 455-464. (doi:10.1677/ erc.1.01086)

38 Fugazzola L, Mannavola D, Cirello V, Vannucchi G, Muzza M, Vicentini L \& Beck-Peccoz P. BRAF mutations in an Italian cohort of thyroid cancers. Clinical Endocrinology 200461 239-243. (doi:10.1111/j. 1365-2265.2004.02089.x)

39 Abrosimov A, Saenko V, Rogounovitch T, Namba H, Lushnikov E, Mitsutake N\& Yamashita S. Different structural components of conventional papillary thyroid carcinoma display mostly identical BRAF status. International Journal of Cancer 2007 120 196-200. (doi:10.1002/ijc.22290)

40 Elisei R, Viola D, Torregrossa L, Giannini R, Romei C, Ugolini C, Molinaro E, Agate L, Biagini A, Lupi C et al. The BRAF(V600E) mutation is an independent, poor prognostic factor for the outcome of patients with low-risk intrathyroid papillary thyroid carcinoma: single-institution results from a large cohort study. Journal of Clinical Endocrinology and Metabolism 201297 4390-4398. (doi:10.1210/jc.2012-1775)

41 Xing M, Alzahrani AS, Carson KA, Viola D, Elisei R, Bendlova B, Yip L, Mian C, Vianello F, Tuttle RM et al. Association between BRAF V600E mutation and mortality in patients with papillary thyroid cancer. Journal of the American Medical Association 2013309 1493-1501. (doi:10.1001/jama.2013.3190)

42 Soares P, Lima J, Preto A, Castro P, Vinagre J, Celestino R, Couto JP, Prazeres H, Eloy C, Maximo V et al. Genetic alterations in poorly differentiated and undifferentiated thyroid carcinomas. Current Genomics 201112 609-617. (doi:10.2174/138920211798120853)

43 Durante C, Puxeddu E, Ferretti E, Morisi R, Moretti S, Bruno R, Barbi F, Avenia N, Scipioni A, Verrienti A et al. BRAF mutations in papillary thyroid carcinomas inhibit genes involved in iodine metabolism. Journal of Clinical Endocrinology and Metabolism 200792 2840-2843. (doi:10.1210/jc.2006-2707)

44 Romei C, Ciampi R, Faviana P, Agate L, Molinaro E, Bottici V, Basolo F, Miccoli P, Pacini F, Pinchera A et al. BRAFV600E mutation, but not RET/PTC rearrangements, is correlated with a lower expression of both thyroperoxidase and sodium iodide symporter genes in papillary thyroid cancer. Endocrine-Related Cancer 200815 511-520. (doi:10.1677/ERC-07-0130)

45 Chakravarty D, Santos E, Ryder M, Knauf JA, Liao XH, West BL, Bollag G, Kolesnick R, Thin TH, Rosen N et al. Small-molecule MAPK inhibitors restore radioiodine incorporation in mouse thyroid cancers with conditional BRAF activation. Journal of Clinical Investigation 2011 121 4700-4711. (doi:10.1172/JCI46382) 
46 Ho AL, Grewal RK, Leboeuf R, Sherman EJ, Pfister DG, Deandreis D, Pentlow KS, Zanzonico PB, Haque S, Gavane S et al. Selumetinibenhanced radioiodine uptake in advanced thyroid cancer. New England Journal of Medicine 2013368 623-632. (doi:10.1056/NEJMoa1209288)

47 Capezzone M, Cantara S, Marchisotta S, Busonero G, Formichi C, Benigni M, Capuano S, Toti P, Pazaitou-Panayiotou K, Caruso G et al. Telomere length in neoplastic and nonneoplastic tissues of patients with familial and sporadic papillary thyroid cancer. Journal of Clinical Endocrinology and Metabolism 201196 E1852-E1856. (doi:10.1210/jc. 2011-1003)

48 Vinagre J, Almeida A, Populo H, Batista R, Lyra J, Pinto V, Coelho R, Celestino R, Prazeres H, Lima L et al. Frequency of TERT promoter mutations in human cancers. Nature Communications 201342185. (doi:10.1038/ncomms3185)

49 Landa I, Ganly I, Chan TA, Mitsutake N, Matsuse M, Ibrahimpasic T, Ghossein RA \& Fagin JA. Frequent somatic TERT promoter mutations in thyroid cancer: higher prevalence in advanced forms of the disease. Journal of Clinical Endocrinology and Metabolism 201398 E1562-E1566. (doi:10.1210/jc.2013-2383)

50 Liu X, Bishop J, Shan Y, Pai S, Liu D, Murugan AK, Sun H, El-Naggar AK $\&$ Xing M. Highly prevalent TERT promoter mutations in aggressive thyroid cancers. Endocrine-Related Cancer 201320 603-610. (doi:10.1530/ERC-13-0210)

51 Horn S, Figl A, Rachakonda PS, Fischer C, Sucker A, Gast A, Kadel S, Moll I, Nagore E, Hemminki K et al. TERT promoter mutations in familial and sporadic melanoma. Science 2013339 959-961. (doi:10.1126/science.1230062)

52 Melo M, da Rocha AG, Vinagre J, Batista R, Peixoto J, Tavares C, Celestino R, Almeida A, Salgado C, Eloy C et al. TERT promoter mutations are a major indicator of poor outcome in differentiated thyroid carcinomas. Journal of Clinical Endocrinology and Metabolism 201499 E754-E765. (doi:10.1210/jc.2013-3734)

53 de Vries MM, Celestino R, Castro P, Eloy C, Maximo V, van der Wal JE, Plukker JT, Links TP, Hofstra RM, Sobrinho-Simoes $\mathrm{M}$ et al. RET/PTC rearrangement is prevalent in follicular Hurthle cell carcinomas. Histopathology 201261 833-843. (doi:10.1111/j.1365-2559.2012. 04276.x)

54 Maximo V, Botelho T, Capela J, Soares P, Lima J, Taveira A, Amaro T, Barbosa AP, Preto A, Harach HR et al. Somatic and germline mutation in GRIM-19, a dual function gene involved in mitochondrial metabolism and cell death, is linked to mitochondrion-rich (Hurthle cell) tumours of the thyroid. British Journal of Cancer 200592 1892-1898. (doi:10.1038/sj.bjc.6602547)

55 Maximo V, Lima J, Prazeres H, Soares P \& Sobrinho-Simoes M. The biology and the genetics of Hurthle cell tumors of the thyroid. Endocrine-Related Cancer 201219 R131-R147. (doi:10.1530/ ERC-11-0354)

56 Liu T, Wang N, Cao J, Sofiadis A, Dinets A, Zedenius J, Larsson C \& $\mathrm{Xu} \mathrm{D}$. The age- and shorter telomere-dependent TERT promoter mutation in follicular thyroid cell-derived carcinomas. Oncogene 2014 33 4978-4984. (doi:10.1038/onc.2013.446)

57 Gandolfi G, Ragazzi M, Frasoldati A, Piana S, Ciarrocchi A \& Sancisi V. TERT promoter mutations are associated with distant metastases in papillary thyroid carcinoma. European Journal of Endocrinology 2015172 403-413. (doi:10.1530/EJE-14-0837)

58 Xing M, Liu R, Liu X, Murugan AK, Zhu G, Zeiger MA, Pai S \& Bishop J. BRAF V600E and TERT promoter mutations cooperatively identify the most aggressive papillary thyroid cancer with highest recurrence. Journal of Clinical Oncology 201432 2718-2726. (doi:10.1200/JCO.2014. $55.5094)$

59 Muzza M, Colombo C, Rossi S, Tosi D, Cirello V, Perrino M, De Leo S, Magnani E, Pignatti E, Vigo B et al. Telomerase in differentiated thyroid cancer: promoter mutations, expression and localization. Molecular and Cellular Endocrinology 2015399 288-295. (doi:10.1016/j. mce.2014.10.019)
60 Sampson E, Brierley JD, Le LW, Rotstein L \& Tsang RW. Clinical management and outcome of papillary and follicular (differentiated) thyroid cancer presenting with distant metastasis at diagnosis. Cancer 2007110 1451-1456. (doi:10.1002/cncr.22956)

61 Liu X, Qu S, Liu R, Sheng C, Shi X, Zhu G, Murugan AK, Guan H, Yu H, Wang $\mathrm{Y}$ et al. TERT promoter mutations and their association with BRAF V600E mutation and aggressive clinicopathological characteristics of thyroid cancer. Journal of Clinical Endocrinology and Metabolism 201499 E1130-E1136. (doi:10.1210/jc.2013-4048)

62 Michaloglou C, Vredeveld LC, Soengas MS, Denoyelle C, Kuilman T, van der Horst CM, Majoor DM, Shay JW, Mooi WJ \& Peeper DS. BRAFE600-associated senescence-like cell cycle arrest of human naevi. Nature 2005436 720-724. (doi:10.1038/nature03890)

63 Bell RJ, Rube HT, Kreig A, Mancini A, Fouse SD, Nagarajan RP, Choi S, Hong C, He D, Pekmezci M et al. Cancer. The transcription factor GABP selectively binds and activates the mutant TERT promoter in cancer. Science 2015348 1036-1039. (doi:10.1126/science.aab0015)

64 Preto A, Singhrao SK, Haughton MF, Kipling D, Wynford-Thomas D \& Jones CJ. Telomere erosion triggers growth arrest but not cell death in human cancer cells retaining wild-type p53: implications for antitelomerase therapy. Oncogene 200423 4136-4145. (doi:10.1038/sj.onc. 1207564)

65 Chiba K, Johnson JZ, Vogan JM, Wagner T, Boyle JM \& Hockemeyer D. Cancer-associated TERT promoter mutations abrogate telomerase silencing. eLife 20154 e07918. (doi:10.7554/eLife.07918)

66 Melo M, da Rocha AG, Vinagre J, Sobrinho-Simoes M \& Soares P. Coexistence of TERT promoter and BRAF mutations in papillary thyroid carcinoma: added value in patient prognosis? Journal of Clinical Oncology 201533 667-668. (doi:10.1200/JCO.2014.59.4614)

67 Levine AJ \& Oren M. The first 30 years of p53: growing ever more complex. Nature Reviews. Cancer 20099 749-758. (doi:10.1038/ nrc2723)

68 Lane D \& Levine A. p53 Research: the past thirty years and the next thirty years. Cold Spring Harbor Perspectives in Biology 20102 a000893. (doi:10.1101/cshperspect.a000893)

69 Ito T, Seyama T, Mizuno T, Tsuyama N, Hayashi T, Hayashi Y, Dohi K, Nakamura $\mathrm{N} \&$ Akiyama M. Unique association of p53 mutations with undifferentiated but not with differentiated carcinomas of the thyroid gland. Cancer Research 199252 1369-1371.

70 Ito T, Seyama T, Mizuno T, Tsuyama N, Hayashi Y, Dohi K, Nakamura N $\&$ Akiyama M. Genetic alterations in thyroid tumor progression: association with p53 gene mutations. Japanese Journal of Cancer Research 199384 526-531. (doi:10.1111/j.1349-7006.1993.tb00171.x)

71 Donghi R, Longoni A, Pilotti S, Michieli P, Della Porta G \& Pierotti MA. Gene p53 mutations are restricted to poorly differentiated and undifferentiated carcinomas of the thyroid gland. Journal of Clinical Investigation 199391 1753-1760. (doi:10.1172/JCI116385)

72 Fagin JA, Matsuo K, Karmakar A, Chen DL, Tang SH \& Koeffler HP. High prevalence of mutations of the p53 gene in poorly differentiated human thyroid carcinomas. Journal of Clinical Investigation 199391 179-184. (doi:10.1172/JCI116168)

73 Dobashi Y, Sakamoto A, Sugimura H, Mernyei M, Mori M, Oyama T \& Machinami R. Overexpression of p53 as a possible prognostic factor in human thyroid carcinoma. American Journal of Surgical Pathology 1993 17 375-381. (doi:10.1097/00000478-199304000-00008)

74 Soares P, Cameselle-Teijeiro J \& Sobrinho-Simoes M. Immunohistochemical detection of p53 in differentiated, poorly differentiated and undifferentiated carcinomas of the thyroid. Histopathology $19942 \mathbf{2 4}$ 205-210. (doi:10.1111/j.1365-2559.1994.tb00511.x)

75 Park KY, Koh JM, Kim YI, Park HJ, Gong G, Hong SJ \& Ahn IM. Prevalences of Gs $\alpha$, ras, p53 mutations and ret/PTC rearrangement in differentiated thyroid tumours in a Korean population. Clinical Endocrinology 199849 317-323. (doi:10.1046/j.1365-2265. 1998.00515.x)

76 Farid P, Gomb SZ, Peter I \& Szende B. bcl2, p53 and bax in thyroid tumors and their relation to apoptosis. Neoplasma 200148 299-301. 
77 Wright PA, Lemoine NR, Goretzki PE, Wyllie FS, Bond J, Hughes C, Roher HD, Williams ED \& Wynford-Thomas D. Mutation of the p53 gene in a differentiated human thyroid carcinoma cell line, but not in primary thyroid tumours. Oncogene 19916 1693-1697.

78 Nikiforov YE, Nikiforova MN, Gnepp DR \& Fagin JA. Prevalence of mutations of ras and p53 in benign and malignant thyroid tumors from children exposed to radiation after the Chernobyl nuclear accident. Oncogene 199613 687-693.

79 Nikiforova MN, Wald AI, Roy S, Durso MB \& Nikiforov YE. Targeted next-generation sequencing panel (ThyroSeq) for detection of mutations in thyroid cancer. Journal of Clinical Endocrinology and Metabolism 201398 E1852-E1860. (doi:10.1210/jc.2013-2292)

80 Ruter A, Dreifus J, Jones M, Nishiyama R \& Lennquist S. Overexpression of p53 in tall cell variants of papillary thyroid carcinoma. Surgery 1996 120 1046-1050. (doi:10.1016/S0039-6060(96)80053-5)

81 Putti TC \& Bhuiya TA. Mixed columnar cell and tall cell variant of papillary carcinoma of thyroid: a case report and review of the literature. Pathology 200032 286-289.

82 Kleer CG, Giordano TJ \& Merino MJ. Squamous cell carcinoma of the thyroid: an aggressive tumor associated with tall cell variant of papillary thyroid carcinoma. Modern Pathology 200013 742-746. (doi:10.1038/modpathol.3880129)

83 Cameselle-Teijeiro J, Menasce LP, Yap BK, Colaco RJ, Castro P, Celestino R, Ruiz-Ponte C, Soares P \& Sobrinho-Simoes M. Cribriformmorular variant of papillary thyroid carcinoma: molecular characterization of a case with neuroendocrine differentiation and aggressive behavior. American Journal of Clinical Pathology 2009131 134-142. (doi:10.1309/AJCP7ULSOVSISBEB)

84 Nakazawa T, Celestino R, Machado JC, Cameselle-Teijeiro JM, Vinagre J, Eloy C, Benserai F, Lameche S, Soares P \& SobrinhoSimoes M. Cribriform-morular variant of papillary thyroid carcinoma displaying poorly differentiated features. International Journal of Surgical Pathology 201321 379-389. (doi:10.1177/1066896912473355)

85 Pita JM, Figueiredo IF, Moura MM, Leite V \& Cavaco BM. Cell cycle deregulation and TP53 and RAS mutations are major events in poorly differentiated and undifferentiated thyroid carcinomas. Journal of Clinical Endocrinology and Metabolism 201499 E497-E507. (doi:10.1210/ jc.2013-1512)
86 Quiros RM, Ding HG, Gattuso P, Prinz RA \& Xu X. Evidence that one subset of anaplastic thyroid carcinomas are derived from papillary carcinomas due to BRAF and p53 mutations. Cancer 2005103 2261-2268. (doi:10.1002/cncr.21073)

87 Evans JJ, Crist HS, Durvesh S, Bruggeman RD \& Goldenberg D. A comparative study of cell cycle mediator protein expression patterns in anaplastic and papillary thyroid carcinoma. Cancer Biology \& Therapy 201213 776-781. (doi:10.4161/cbt.20560)

88 Pilotti S, Collini P, Del Bo R, Cattoretti G, Pierotti MA \& Rilke F. A novel panel of antibodies that segregates immunocytochemically poorly differentiated carcinoma from undifferentiated carcinoma of the thyroid gland. American Journal of Surgical Pathology 199418 1054-1064. (doi:10.1097/00000478-199410000-00009)

89 Moretti F, Farsetti A, Soddu S, Misiti S, Crescenzi M, Filetti S, Andreoli M, Sacchi A \& Pontecorvi A. p53 re-expression inhibits proliferation and restores differentiation of human thyroid anaplastic carcinoma cells. Oncogene 199714 729-740. (doi:10.1038/sj.onc. 1200887)

90 DeLellis RA, Lloyd RV, Heitz PU \& Eng C. In WHO Classification of Tumours. Pathology and Genetics of Tumours of Endocrine Organs. Lyon IARC Press, 2004.

91 Cameselle-Teijeiro J, Rodríguez-Pérez I, Celestino R, Eloy C, Piso Neira I, Abdulkader Nallib I, Soares P \& Sobrino-Simões M. Hobnail/ micropapillary variant of papillary thyroid carcinoma: Evidence of progression to undifferentiated carcinoma with molecular analysis. Virchows Archiv 2015467 (Supplement 1) S69.

92 Mazeh H. MicroRNA as a diagnostic tool in fine-needle aspiration biopsy of thyroid nodules. Oncologist 201217 1032-1038. (doi:10.1634/ theoncologist.2012-0013)

93 Jendrzejewski J, He H, Radomska HS, Li W, Tomsic J, Liyanarachchi S, Davuluri RV, Nagy R \& de la Chapelle A. The polymorphism rs944289 predisposes to papillary thyroid carcinoma through a large intergenic noncoding RNA gene of tumor suppressor type. PNAS 2012109 8646-8651. (doi:10.1073/pnas.1205654109)

94 Kentwell J, Gundara JS \& Sidhu SB. Noncoding RNAs in endocrine malignancy. Oncologist 201419 483-491. (doi:10.1634/theoncologist. 2013-0458)

Received 18 June 2015

Revised version received 7 October 2015

Accepted 28 October 2015 